\title{
Nanoscale Analysis of Randall's Plaques by Electron Energy Loss Spectromicroscopy: Insight in Early Biomineral Formation in Human Kidney
}

\begin{abstract}
Clément Gay ${ }^{1}$, Emmanuel Letavernier ${ }^{2,3,4}$, Marie-Christine Verpont ${ }^{2,3}$, Michael Walls ${ }^{1}$, Dominique Bazin ${ }^{5}$, Michel Daudon 2,3,4, Nadine Nassif6, Odile Stéphan ${ }^{1}$, Marta de Frutos ${ }^{\text {1* }}$
\end{abstract}

${ }^{1}$ Laboratoire de Physique des Solides, CNRS UMR 8502, Université de Paris-Saclay, F91405, Orsay, France.

2 Sorbonne Université, UPMC Univ Paris 06, UMR S 1155, F-75020, Paris, France

${ }^{3}$ INSERM, UMR S 1155, F-75020, Paris, France

${ }^{4}$ Physiology Unit, APHP, Hôpital Tenon, F-75020, Paris, France

${ }^{5}$ Laboratoire de Chimie Physique, UMR 8000-CNRS, Université de Paris-Saclay, F-91405

Orsay, France

${ }^{6}$ Sorbonne Université, CNRS, Collège de France, Laboratoire de Chimie de la Matière Condensée de Paris (LCMCP), 4 place Jussieu, F-75005, Paris, France

\section{Supplementary Information}




\section{Analysis of kidney stones and papilla by FTIR}

Three different samples have been chosen among the extensive collection of macroscopic kidney stones at the Tenon hospital that was analyzed by FTIR spectroscopy. ${ }^{1}$ Concerning the mineral composition, three different phases were detected: whitlockite, CHA and ACCP. Whitlockite is a calcium and magnesium phosphate phase that can be distinguished by the typical absorbance peak at $1078-1080 \mathrm{~cm}^{-1}$ corresponding to the $\mathrm{HPO}_{4}{ }^{2-}$ stretching vibration band. The crystalline form of CHA was distinguished from the amorphous phase (ACCP) by the presence of a shoulder (marked by a star in Figure S1) due to the $\mathrm{PO}_{4}{ }^{3-}$ stretching vibration band located at $\sim 1033 \mathrm{~cm}^{-1}$. Carbonate ions are mainly detected by their stretching vibration band around $1325 \mathrm{~cm}^{-1}$ and their bending band at $875 \mathrm{~cm}^{-1}$. Proteins are mainly detected by their amide bands at $\sim 1550$ and $1650 \mathrm{~cm}^{-1}$.

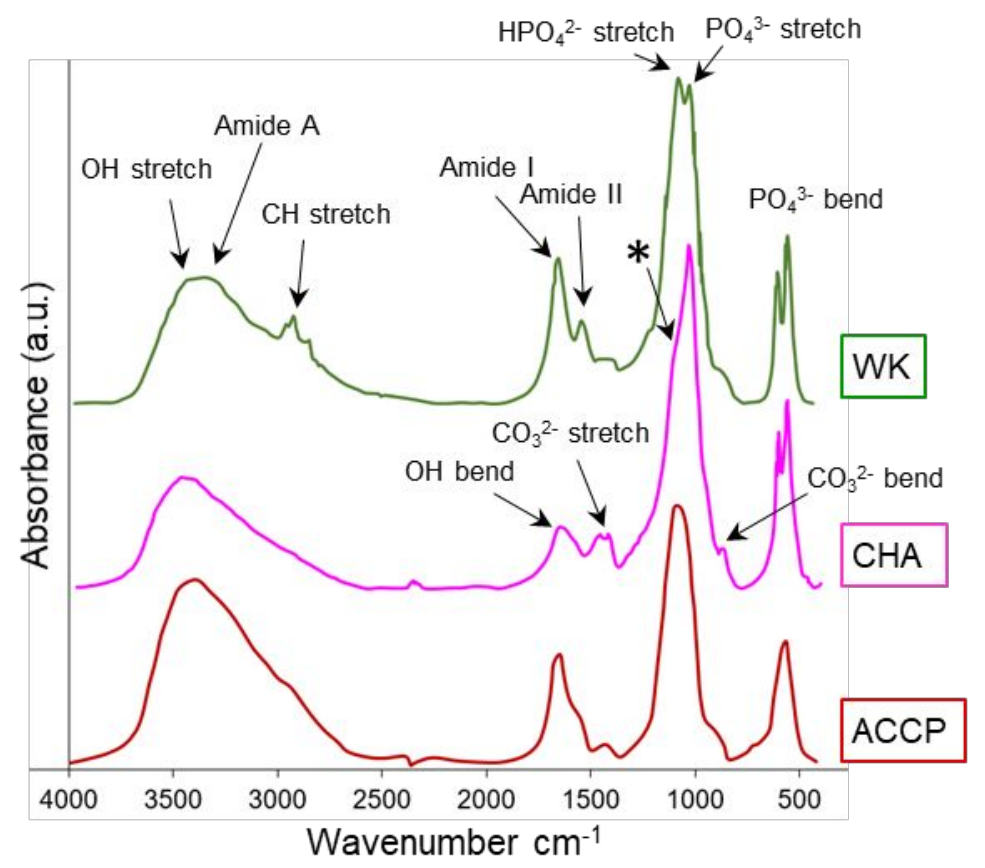

Figure S1: FTIR spectra of kidney stones composed of amorphous carbonated calcium phosphate (ACCP), carbonated hydroxyapatite (CHA), whitlockite (WK).

\section{Electron dose effect on EELS features for mineral, organic compounds and resin}

Biological samples are known to be highly sensitive to beam damage when imaged by electron microscopy. For biominerals, the analysis of chemical composition by EELS implies to discriminate between the fingerprints corresponding to the minerals but also the fragile 
organic constituents composing the specimen. A sample degradation may result in the loss of the spectral features and the information concerning the composition. In our study, the EELS spectra have been acquired for electron doses in the range between $5 \times 10^{5}$ and $2 \times 10^{7} \mathrm{e}^{-} / \mathrm{nm}^{2}$ to establish the conditions appropriated to analyze our samples.

Radiation induced damage on calcium compounds has been investigated in previous studies. ${ }^{2,3}$ These authors report the apparition of a characteristic peak at $530 \mathrm{eV}$ for the oxygen K-edge at doses above $10^{4} \mathrm{e}^{-} / \mathrm{nm}^{2}$. In our acquisitions, despite data were acquired at electron doses three order of magnitude higher than the critical value, such additional peak was detected neither on pure synthetic hydroxyapatite (HA), nor on calcite (CAL) for doses up to $2 \times 10^{7} \mathrm{e}^{-}$ $/ \mathrm{nm}^{2}$ (Figure S2).

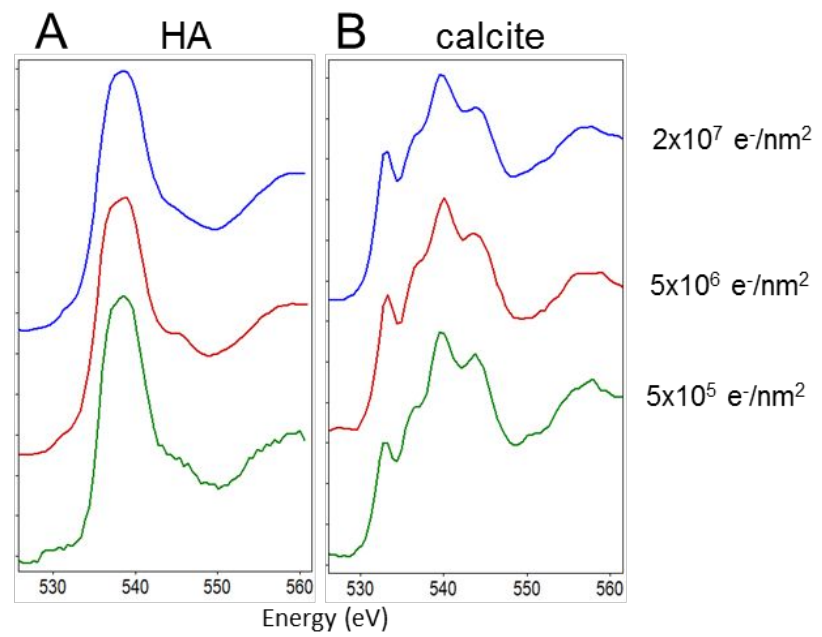

Figure S2: Oxygen K-edge as a function of the electron dose for (A) hydroxyapatite (HA) and (B) calcite (CAL). No difference was observed due to induced beam damage from $5 \times 10^{5}$ to $2 \times 10^{7} e^{-} / \mathrm{nm}^{2}$.

The better preservation of the specimen in our experiments could be related to two parameters: the temperature of the sample holder and the dose rate. In our setup, the temperature was $\sim 170 \mathrm{~K}$ compared to room temperature in previous studies. Cooling organic specimens to liquid nitrogen temperature is known to reduce radiation effects and decrease mass loss up to a factor of $100 .{ }^{4}$ Another important parameter is the probe diameter. For a given electron dose and pixel size, larger diameters result in lower dose rates and better preservation of the sample as shown by Bres et al. ${ }^{5}$ These authors report no mass loss and no extra-peak on hydroxyapatite at room temperature for a beam diameter equal to $4 \mathrm{~nm}$ and electron doses below $10^{8} \mathrm{e}-/ \mathrm{nm}^{2}$ (dose rate $\sim 10^{7} \mathrm{e}^{-} / \mathrm{nm}^{2} \mathrm{~s}$ ). The probe size and dose rate were not detailed in ${ }^{2,3}$ but the probe for 
a corrected STEM microscope in standard acquisition conditions is usually much smaller than for the VG STEM used in our experiments (probe diameter of $\sim 1 \mathrm{~nm}$ and dose rate $\sim 10^{8} \mathrm{e}^{-}$ $\left./ \mathrm{nm}^{2} \mathrm{~s}\right)$.

EELS fingerprints corresponding to non-mineral compounds were analyzed on papillae specimens in regions without calcifications. Sections contain two types of compounds: the embedding resin and the organic compounds composing the kidney tissue. In order to analyze the dose effect for each compound and as they are mixed together in the specimen Hyperspectral Unmixing was performed using Vertex Component Analysis (VCA). ${ }^{6}$ The two extracted components correspond respectively to the resin (Figure S3A) and to the tissue constituents (Figure S4B). When measured by X-ray absorption, the signatures for the carbon, nitrogen and oxygen K-edge were shown to be specific for each biomolecule (proteins, nucleic acids, lipids, saccharides). ${ }^{7-10}$ In our data, no variation was detected between the spectra associated with the different cellular organelles that contain variable amounts of each biomolecule. For all electron doses (Figure S3), the fine structure does not display clear similarities with X-ray data allowing to determine the exact composition. The possible reasons are the presence of a mixture of molecules, the low energy resolution and the beam damage effects. Lower doses have been used in previous EELS measurements on organic compounds in hybrid nanoparticles ${ }^{11}$ but a strong defocus was needed to increase the beam size to values not compatible with the nanometer spatial resolution required in the present study. Nevertheless, in our experimental conditions, the signature of the kidney tissue was easily distinguished from the resin and it was possible to map the presence of organic compounds in the biomineral at all electron doses. The difference between both is even more pronounced for the highest dose indicating that the resistance to damage is different for both compounds. 


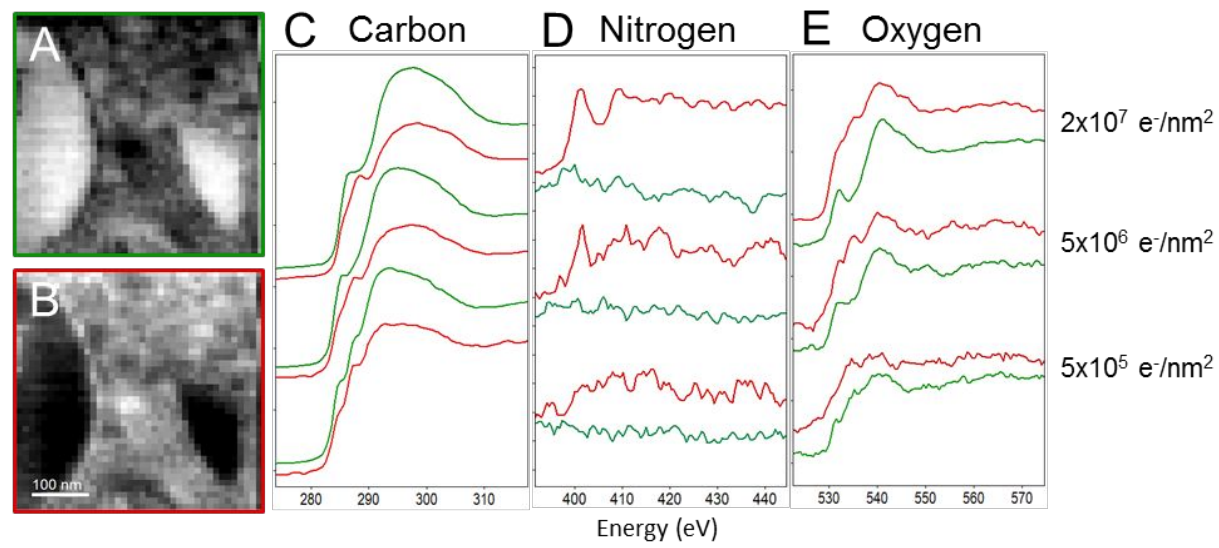

Figure S3: Dose effect on carbon (C), nitrogen (D) and oxygen (E) K-edges for kidney tissue embedded in resin. Using VCA decomposition, two components were extracted corresponding respectively to the regions composed of resin (A) and organic compounds (B). The radiation induced damage induces a variation of the edge features depending on the electron dose. The difference between the two regions is clearly visible even at the highest dose.

\section{Fingerprinting for organic compounds and resin.}

Data presented in Figure S4 were recorded for an electron dose of $5 \times 10^{6} \mathrm{e}^{-} / \mathrm{nm}^{2}$ on a kidney region without calcifications. Resin and kidney tissue contain carbon, nitrogen and oxygen but can be discriminated by the feature of oxygen K-edge (peaks $o$ and $p$ in Figure S4C) and by the nitrogen signal that is not detected on the resin. Resin contains a lower quantity of nitrogen than the organic compounds. A difference was also visible on carbon: the main features are a peak at $\sim 285 \mathrm{eV}$ (peak $c$ in Figure $\mathrm{S} 4 \mathrm{~A}$ ) for resin and at $\sim 287-288 \mathrm{eV}$ (peak $d$ in Figure S4A) for the organic compounds. In previous studies, this last peak was attributed to carbonyl group and used to identify the proteins. In X-ray absorption measurements, the signature of the carbon edge was shown to be specific to each biomolecule ${ }^{7}$ and the position of the sharp peak associated to the $\mathrm{C} 1 \mathrm{~s} \rightarrow \pi^{*}$ transition varies with the chemical group determining the $\mathrm{C}$ bonding environment: $286.8 \mathrm{eV}$ for phenolic groups or ketonic groups, $288.2 \mathrm{eV}$ for amide carbonyl groups in proteins and for carboxylic groups in polysaccharides, at $289.5 \mathrm{eV}$ for $\mathrm{C}=$ O groups in nucleic acids. ${ }^{12,13}$ For the resin, a peak related to aromatic groups was also reported at $285 \mathrm{eV}$ together with a peak at $288 \mathrm{eV} .{ }^{14}$ Compared to X-rays data, EELS spectra for organic compounds always exhibit modified signatures due to the beam damage. ${ }^{14,15}$ In our measurements, the carbon peak at $285 \mathrm{eV}$ is reinforced due to the formation of unsaturated 
bonds under the beam for resin and biomolecules as already reported. ${ }^{14}$ Concerning the peak around $287-288 \mathrm{eV}$, due to damage combined to low energy resolution, no difference was observed on its position between cell nucleus (nucleic acids and proteins) compared to membranes (lipids and proteins). In the same way, no specificity was observed on the nitrogen and oxygen edges even at the lower dose used for our acquisitions. Another possible explanation for the absence of variation is an effect of the osmium tetraoxide that is a strong oxidizing agent able to react with functional groups and to alter the coordination environment of the carbon bonds. ${ }^{16}$ As a consequence the exact nature of the organic compounds found in the specimen cannot be determined from EELS data but their presence can be clearly discriminated from the resin by examining the features of carbon, nitrogen and oxygen edges.
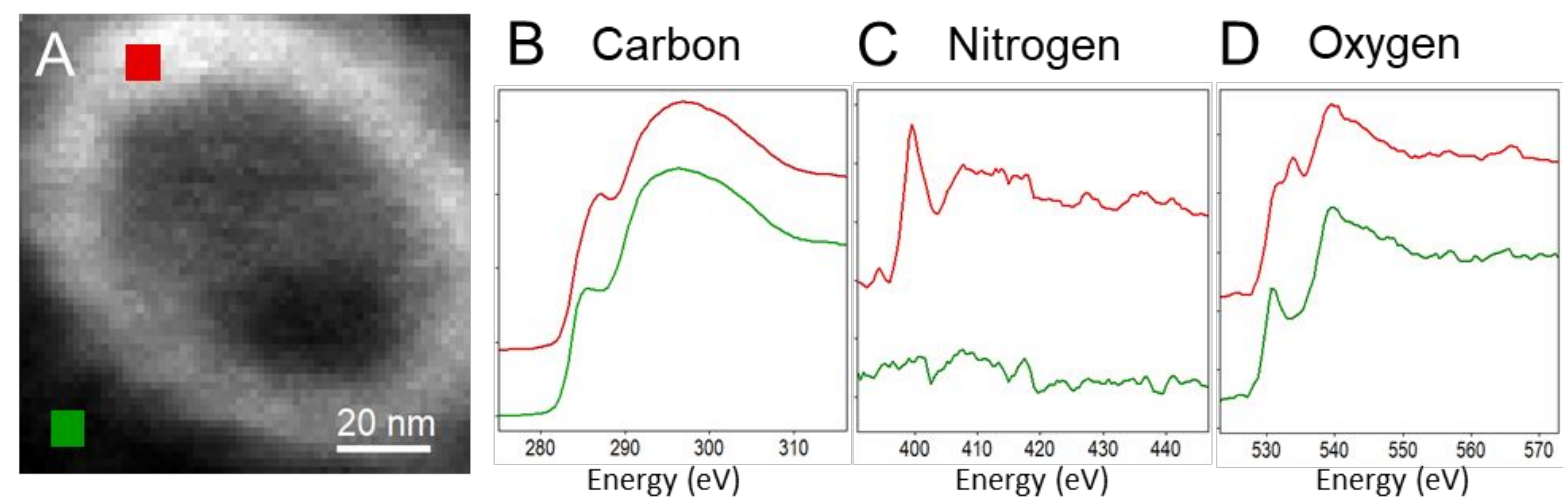

Figure S4: (A) STEM-HAADF image of a kidney region without mineral. The highest contrast corresponds to kidney tissue constituents and the darkest to embedding resin. EEL spectra of carbon (B), nitrogen (C) and oxygen (D) edges for the organic compounds forming the kidney tissue (red curve) and the embedding resin (green curve). 
Table S1: EELS characteristic features for mineral, organic compounds and resin

\begin{tabular}{|c|c|c|c|}
\hline & Edge & Label & Energy for peak maximum \\
\hline \multirow[t]{3}{*}{ HA } & $\mathrm{P} \mathrm{L}_{23}$-edge & $\begin{array}{l}\mathrm{a} \\
\mathrm{a}^{*} \\
\mathrm{~b}\end{array}$ & $\begin{array}{l}138 \mathrm{eV} \\
147 \mathrm{eV} \\
160 \mathrm{eV}\end{array}$ \\
\hline & $\mathrm{Ca} \mathrm{L}_{23}$-edge & $\mathrm{g}$ & $349 \mathrm{eV}-352 \mathrm{eV}$ \\
\hline & O K-edge & $\mathrm{i}$ & $538 \mathrm{eV}$ \\
\hline \multirow[t]{3}{*}{ CAL } & C K-edge & $\begin{array}{l}\text { e } \\
f\end{array}$ & $\begin{array}{l}290 \mathrm{eV} \\
301 \mathrm{eV}\end{array}$ \\
\hline & $\mathrm{Ca} \mathrm{L}_{23}$-edge & $\mathrm{g}$ & $349 \mathrm{eV}-352 \mathrm{eV}$ \\
\hline & O K-edge & $\mathrm{j}$ & $\begin{array}{l}533 \mathrm{eV} \\
537 \mathrm{eV} \\
540 \mathrm{eV} \\
545 \mathrm{eV}\end{array}$ \\
\hline \multirow[t]{5}{*}{$\mathrm{ACCP}, \mathrm{CHA}, \mathrm{WK}$} & $\mathrm{P} \mathrm{L}_{23}$-edge & $\begin{array}{l}\mathrm{a} \\
\mathrm{a}^{*} \\
\mathrm{~b}\end{array}$ & $\begin{array}{l}138 \mathrm{eV} \\
147 \mathrm{eV} \\
160 \mathrm{eV}\end{array}$ \\
\hline & C K-edge & $\begin{array}{l}\mathrm{c} \\
\mathrm{d} \\
\mathrm{e}\end{array}$ & $\begin{array}{l}285 \mathrm{eV} \\
287 \mathrm{eV} \\
290 \mathrm{eV}\end{array}$ \\
\hline & $\mathrm{Ca} \mathrm{L}_{23}$-edge & $\mathrm{g}$ & $349 \mathrm{eV}-352 \mathrm{eV}$ \\
\hline & N K-edge & $\mathrm{h}$ & $400 \mathrm{eV}$ \\
\hline & O K-edge & $\mathrm{k}$ & $538 \mathrm{eV}$ \\
\hline \multirow[t]{2}{*}{ Embedding resin (RES) } & C K-edge & $\mathrm{d}$ & $285 \mathrm{eV}$ \\
\hline & O K-edge & $\mathrm{p}$ & $531 \mathrm{eV}$ \\
\hline \multirow[t]{3}{*}{ Organic compound (ORG) } & C K-edge & $\mathrm{c}$ & $287 \mathrm{eV}$ \\
\hline & N K-edge & $\mathrm{h}$ & $400 \mathrm{eV}$ \\
\hline & O K-edge & o & $533 \mathrm{eV}$ \\
\hline
\end{tabular}




\section{REFERENCES}

(1) Estepa, L.; Daudon, M. Contribution of Fourier Transform Infrared Spectroscopy to the Identification of Urinary Stones and Kidney Crystal Deposits. Biospectroscopy 1997, 3, 347-369.

(2) Nitiputri, K.; Ramasse, Q. M.; Autefage, H.; McGilvery, C. M.; Boonrungsiman, S.; Evans, N. D.; Stevens, M. M.; Porter, A. E. Nanoanalytical Electron Microscopy Reveals a Sequential Mineralization Process Involving Carbonate-Containing Amorphous Precursors. ACS Nano 2016, 10, 6826-6835.

(3) Kłosowski, M. M.; Friederichs, R. J.; Nichol, R.; Antolin, N.; Carzaniga, R.; Windl, W.; Best, S. M.; Shefelbine, S. J.; McComb, D. W.; Porter, A. E. Probing Carbonate in Bone Forming Minerals on the Nanometre Scale. Acta Biomater. 2015, 20, 129-139.

(4) Egerton, R. F.; Li, P.; Malac, M. Radiation Damage in the TEM and SEM. Micron 2004, 35, 399-409.

(5) Brès, É. F.; Reyes-Gasga, J.; Rey, C.; Michel, J. Probe Size Study of Apatite Irradiation in Stem. Eur. Phys. J. Appl. Phys. 2014, 67, 20401.

(6) Nascimento, J. M. P.; Dias, J. M. B. Vertex Component Analysis: A Fast Algorithm to Unmix Hyperspectral Data. IEEE Trans. Geosci. Remote Sens. 2005, 43, 898-910.

(7) Lawrence, J. R.; Swerhone, G. D. W.; Leppard, G. G.; Araki, T.; Zhang, X.; West, M. M.; Hitchcock, A. P. Scanning Transmission X-Ray, Laser Scanning, and Transmission Electron Microscopy Mapping of the Exopolymeric Matrix of Microbial Biofilms. Appl. Environ. Microbiol. 2003, 69, 5543-5554.

(8) Kirtley, S. M.; Mullins, O. C.; Chen, J.; van Elp, J.; George, S. J.; Chen, C. T.; O'Halloran, T.; Cramer, S. P. Nitrogen Chemical Structure in DNA and Related Molecules by X-Ray Absorption Spectroscopy. Biochim. Biophys. Acta BBA - Gene Struct. Expr. 1992, 1132, 249-254.

(9) Zubavichus, Y.; Shaporenko, A.; Grunze, M.; Zharnikov, M. NEXAFS Spectroscopy of Homopolypeptides at All Relevant Absorption Edges: Polyisoleucine, Polytyrosine, and Polyhistidine. J. Phys. Chem. B 2007, 111, 9803-9807.

(10) Zubavichus, Y.; Shaporenko, A.; Korolkov, V.; Grunze, M.; Zharnikov, M. X-Ray Absorption Spectroscopy of the Nucleotide Bases at the Carbon, Nitrogen, and Oxygen K-Edges. J. Phys. Chem. B 2008, 112, 13711-13716.

(11) Schooneveld, M. M. van; Gloter, A.; Stephan, O.; Zagonel, L. F.; Koole, R.; Meijerink, A.; Mulder, W. J. M.; Groot, F. M. F. de. Imaging and Quantifying the Morphology of an Organic-Inorganic Nanoparticle at the Sub-Nanometre Level. Nat. Nanotechnol. 2010, 5, 538-544.

(12) Benzerara, K.; Yoon, T. H.; Tyliszczak, T.; Constantz, B.; Spormann, A. M.; Brown, G. E. Scanning Transmission X-Ray Microscopy Study of Microbial Calcification. Geobiology 2004, 2, 249-259.

(13) Solomon, D.; Lehmann, J.; Harden, J.; Wang, J.; Kinyangi, J.; Heymann, K.; Karunakaran, C.; Lu, Y.; Wirick, S.; Jacobsen, C. Micro- and Nano-Environments of Carbon Sequestration: Multi-Element STXM-NEXAFS Spectromicroscopy Assessment of Microbial Carbon and Mineral Associations. Chem. Geol. 2012, 329, $53-73$.

(14) Goode, A. E.; Porter, A. E.; Ryan, M. P.; McComb, D. W. Correlative Electron and XRay Microscopy: Probing Chemistry and Bonding with High Spatial Resolution. Nanoscale 2015, 7, 1534-1548. 
(15) Braun, A.; Kubatova, A.; Wirick, S.; Mun, S. B. Radiation Damage from EELS and NEXAFS in Diesel Soot and Diesel Soot Extracts. J. Electron Spectrosc. Relat. Phenom. 2009, 170, 42-48.

(16) Kłosowski, M. M.; Carzaniga, R.; Abellan, P.; Ramasse, Q.; McComb, D. W.; Porter, A. E.; Shefelbine, S. J. Electron Microscopy Reveals Structural and Chemical Changes at the Nanometer Scale in the Osteogenesis Imperfecta Murine Pathology. ACS Biomater. Sci. Eng. 2017, 3, 2788-2797. 